\title{
The Study of Key Factors Governing the Use of Contraceptives in Rural Area of Sonbhadra District, India
}

\author{
Dr. Vimalesh Kumar Singh \\ Assistant Professor, R.K.Singh P.G.College Kalwari, Mirzapur, U.P.
}

\begin{abstract}
The present study aims at examining the recent transformation of the rural society, which is caste ridden, conservative and sluggish to adopt new innovations. This research work is mainly based on primary data collected through interview schedules from 365 married women respondents on stratified random basis from Sonbhadra District, Uttar Pradesh. The present paper also highlights the position of spouse on the practice of family planning methods. This study was undertaken to know the extent of awareness among married women towards the various aspects of family planning. It was found that majority of the respondents had knowledge and awareness about various aspects of family planning but its adoption is of low magnitude. Women were the major users of permanently contraceptives (tubectomy) as contrary to men. Some women were found with the use of oral pills but the use of loops, condom and copper-T was almost slugest utilization in the study area.
\end{abstract}

Keywords: Rural community, socio-economic profile, education level, age group, and contraceptive methods, Sonbhadra district.

\section{Introduction:}

Rapid population growth continues to be a major concern of Indian development planning. During the last decade (1991-2001) India's population has increased by 182.32 million (18.23 million per year). This number is sufficient enough to neutralise any efforts of economic development. India may soon become the most populous country of the world, overtaking China within next 20 to 30 years. Although India has made good efforts to stabilize the population for the last 60 years through National Family Welfare Programme launched in 1951 yet due to the poor performance of BIMARU states, India could not achieve the goal of population stabilization. Although India was the first country to adopt family planning as a National programme during 1951-52, the demographic situation in the country is still a matter of grave concern. The low use of spacing methods is reflected in early child bearing and short birth intervals. Wherever, services exist, women are constrained for using the family planning methods by cultural mores or pressure to rebuild the population (Singh et al, 2007). A close association between family planning knowledge, attitude and behavior was observed by Pandey and Singh 2001 which indicated that proper awareness of adequate means of family planning, its effectiveness and adequate source of information exercised positive impact on developing favorable attitude which motivated females to adopt family planning behavior. Besides programme factor, number of socioeconomic, demographic, cultural and community factors besides programme factors, contribute to the level use of family planning (Rajaretanam, 1995). Contraceptive use is higher in urban areas than in rural areas because urban women are more educated than rural women. Not only urban residence, educational level, and regular media exposure have independent, positive effects on contraceptive use but also husband's education too matters. In all states Muslim have lower use rates than Hindu (Ramesh et al, 1996).

A WHO expert committee in 1975 had proposed five methods to evaluate the success of family welfare programme. One of them is the evaluation of knowledge and attitude and people. The knowledge and attitude of people towards family planning methods are important determinants in the adoption of family planning methods by them (Reddy et. al, 2003, p.63). It plays a significant role in assessing various dimensions of problem related to contraception, maternal and child health care and provides a platform for making an effective policy for the success of family welfare programme in the concerned area.

The adoption of family welfare programme depends on accessibility to health facility, availability and affordability of health services and a host of other factors such as socio-economic and demographic profile of the respondents (Banerjee, 2004, p.54). Hense, for the analysis of knowledge and attitude of respondents towards adoption of family welfare programme in the study area, it is pertinent to know the socio-economic and demographic characteristics of the respondents. To procure requisite data and to arrive at certain conclusions, a detailed survey was conducted between August 2007 and February 2008. A comprehensive questionnaire (Appendix) was employed to interview 560 ever married respondents (one from each household) from 16 villages of the study area. 
The control of fertility and use of family planning or contraceptive methods are of vital importance for all developing nations, like India, and district, like Sonbhadra, where high fertility and declining moderate mortality rates have led to an explosive growth of population. In other words, due to still untamed fertility rates hampering the human goals of development and well being, these nations/states believer the need for planned motherhood, which refers to adoption of some birth control measures. Even though India in 1952 became the first country of the world to adopt an official family planning programme, the results are not entirely satisfactory. In regarding, knowledge is evident due to differentials in socio-economic profile, educational level, and type of infrastructure availability. In India the progamme promotes responsible motherhood with a two child family norm (regardless of the sex of the child) through the voluntary use of contraceptive methods and variety of maternal and child health care schemes (Family Planning Programme in India, 1991-92). The contraceptive methods provided by the programme are, intrauterine devices (IUD), tubectomy, vasectomy, oral pills, condoms, etc. Besides, free services are provided for induced abortion or medical termination of pregnancy (MTP) as well. The family planning services are promulgated extensively through a network of Sub-Centres, Primary Health Centres, and Community Health Centres in rural areas, and hospitals, dispensaries in urban areas.

\section{Objective Of The Study}

1. To study the level of use contraceptive methods and socio-economic status.

2. To analyze factor affecting contraceptive use to different educational level.

3. To study the linkage between contraceptive use and educational level and income groups.

\section{STUDY AREA}

\section{Material And Methods}

Sonbhadra district is located in the Eastern (U.P.), It is situated between latitude $23^{\circ} 51^{\prime} 22^{\prime}$ ' to $24^{\circ} 53^{\prime} 16^{\prime \prime} \mathrm{N}$ and longitude $82^{\circ} 31^{\prime} 55^{\prime \prime}$ to $83^{\circ} 33^{\prime} 45^{\prime \prime} \mathrm{E}$ and spread in an area of $6788 \mathrm{~km}^{2}$. The study area is divided into 8 community development blocks. It has a population of about 1463519 (2001, Census) and density 215 persons per $\mathrm{km}^{2}$. Scheduled castes population is 43.14 per cent of total population. It is situated in the Eastern part of state (U.P.), India

\section{DATA SOURCE}

The survey collected information from Sonbhadra district representative sample of 150 households. For the purpose of this study a sample of 365 married women age group 18-49 years, and different socio-economic profiles, educational level, community castes were randomly selected women interviewed. The study sample comprised Scheduled casts, other backward cast and general community belonging to this district. A nuclear family was taken as the unit of the study. For data collection, structured schedules developed for the purpose were utilized in addition to drawing genealogies and participant observation.

\section{TOOL AND TECHNIQUE}

1. The present study is based on primary and secondary data. All data analysis was entered into a personal computer and analysis was done through SPSS version 16.0.

2. For this study, kind of use contraceptive as covariates along with age, income, occupation, and education level of respondents were also considered as the dependent variables.

3. Univariate, one-way ANOVA, t-test (significant level) and standard deviation analysis was carried out method used.

Note: In one-way ANOVA analysis, we have one independent variable of factors and we are interested in knowing their effect on the same dependent variable.

\section{LIMITATION OF THE STUDY}

The collection of data on some of the items was very difficult to get, especially in case of income. Because most of the agricultural households were illiterate and it was very difficult for them to give correct answer of all the questions in the interview schedule regarding income and knowledge of family planning methods.

During the data collection, even though our focus was on poor casts and families, laboure households, we came across that most of the households were also engaged in non-agricultural work. When we were analyzing the data on income, we found it difficult to differentiate the non-agricultural income from the income earned by agricultural activities. 


\section{Results And Discussion}

Table 1 shows caste wise respondents in the study area where majority 39.7 per cent of the total respondents belonging to General caste fallowed by 34.2 percent $\mathrm{OBC}$ and 10.3 percent S.C. respondents.

Table 1: Caste wise respondents involve under the study

\begin{tabular}{|l|r|r|}
\hline \multicolumn{1}{|c|}{ Castes } & Frequency & Percent \\
\hline S.C. & 38 & 10.3 \\
\hline O.B.C. & 125 & 34.2 \\
\hline General & 145 & 39.7 \\
\hline Total & 308 & 84.2 \\
\hline Missing & 57 & 15.6 \\
\hline Grand total & 365 & 100.0 \\
\hline
\end{tabular}

Note: Missing value is also Muslim respondents. They are not using family planning methods because him religious restriction.

Table 2 depicts that adoption of family planning methods is negatively related with castes. Among specific methods, the percentage of awareness of family planning methods users have decreased with the caste General to SC. Muslims do not adopt permanent method (sterilization) because of their religious taboo.

Table 2: Caste wise awareness about the family planning methods

\begin{tabular}{|l|l|r|r|r|r|r|r|}
\hline \multicolumn{2}{|c|}{ Religion/Caste } & \multicolumn{5}{|c|}{ Family planning methods } & Total \\
\cline { 3 - 8 } \multicolumn{2}{|c|}{} & Oral pills & Nusbandi & \multicolumn{1}{c|}{ Condome } & Tubectomy & Others & \\
\hline \multirow{3}{*}{ Hindu } & General & 69.66 & 100.00 & 48.97 & 33.79 & 1.38 & 145 \\
\cline { 2 - 8 } & O.B.C. & 42.20 & 100.00 & 48.80 & 35.20 & 3.20 & 125 \\
\cline { 2 - 8 } & S.C. & 31.58 & 100.00 & 39.48 & 39.48 & - & 38 \\
\hline Muslim & - & 42.10 & 100.00 & 56.61 & 29.82 & - & 57 \\
\hline Total & 52.33 & 100.00 & 47.40 & 34.25 & 1.64 & 365 \\
\hline
\end{tabular}

Source: personal survey

Table 3 reveals that contraceptive prevalence is higher among General caste $(51.66 \%)$ than OBC $(41.06 \%)$ and SC (7.28\%). Adoption of temporary method (especially oral pills) is slightly higher in general caste $(35.90 \%)$ than in OBC (33.87\%) and SC (27.27). This table is also displays that adoption of permanent method (Nusbandi) of family planning methods is higher in just reveres condition lover castes (54.55\%) than in other backward castes $(45.16 \%)$ and general castes in only $(44.87 \%)$.

Table 3: Caste wise use of family planning methods

\begin{tabular}{|l|r|r|r|r|r|r|}
\hline \multicolumn{1}{|c|}{ Caste } & \multicolumn{1}{c|}{ Oral pills } & \multicolumn{1}{c|}{ Nusbandi } & \multicolumn{1}{c|}{ Tubectomy } & \multicolumn{1}{c|}{ Others } & \multicolumn{1}{c|}{ Total } & \multicolumn{1}{c|}{ of users } \\
\hline General & 35.90 & 44.87 & 16.67 & 2.56 & 78 & 51.66 \\
\hline O.B.C. & 33.87 & 45.16 & 14.52 & 6.45 & 62 & 41.06 \\
\hline S.C. & 27.27 & 54.55 & 18.18 & - & 11 & 7.28 \\
\hline Total & 52 & 69 & 24 & 6 & 151 & 100.00 \\
\hline
\end{tabular}

Women's education influences their partner's attitude towards adoption of a family planning method. Demonstrates that literacy has profound bearing on adoption of family planning methods. Literate women's are more informed about the choice of contraception and problems associated with various methods. Educated women are in a better situation to take a decision about contraception.

Table 4: Education wise use of family planning methods

\begin{tabular}{|l|r|r|r|r|r|r|}
\hline \multicolumn{1}{|c|}{ Education } & \multicolumn{1}{c|}{ Oral pills } & \multicolumn{1}{c|}{ Nusbandi } & Tubectomy & Others & \multicolumn{1}{c|}{ Total } & \% of users \\
\hline Illiterate & 21.21 & 72.73 & 6.06 & - & 33 & 21.85 \\
\hline Up to Primary & 17.95 & 64.10 & 10.26 & 7.69 & 39 & \multirow{2}{*}{78.15} \\
\cline { 1 - 6 } Up to High school & 43.48 & 26.09 & 30.43 & - & 23 & \\
\hline Above High school & 50.00 & 25.00 & 19.64 & 5.36 & 56 & \\
\cline { 1 - 6 } Total & 52 & 69 & 24 & 6 & 151 & 100.00 \\
\hline
\end{tabular}

Table 4 shows that with an increase in the educational level of women's the proportion of family planning adoption also increases (from $21.85 \%$ in illiterate to $78.15 \%$ in educated women's). Illiterate women's give 
more preference to permanent method due to lack of proper knowledge on use of spacing methods while literate women's give more preference to the temporary or spacing methods.

Table 5 portrays the reasons of not adopting any family planning method by never users $(n=157)$. Rumours which are told and retold through the communities have contributed to low contraceptive acceptance (Nag M., 1984).

Table 5: Caste wise never users of contraception with reasons

\begin{tabular}{|l|r|r|r|r|r|}
\hline \multicolumn{1}{c|}{$\begin{array}{c}\text { Reasons for never use } \\
\text { of contraception* }\end{array}$} & \multicolumn{2}{c|}{ Caste wise respondents } & \multicolumn{1}{c|}{$\begin{array}{c}\text { Total } \\
\text { No. }\end{array}$} & $\begin{array}{c}\text { \% of never users } \\
\text { by causes }\end{array}$ \\
\cline { 2 - 5 } & General & \multicolumn{1}{c|}{ OBC } & \multicolumn{1}{c|}{ SC } & 19 & 12.10 \\
\hline Scared of side effects & 14.08 & 12.70 & 3.70 & 19 & 34.40 \\
\hline Need of boy & 36.62 & 28.57 & 37.04 & 54 & 22.30 \\
\hline Ignorance (About use) & 30.99 & 11.11 & 22.22 & 35 & 14.01 \\
\hline No Knowledge & - & 25.40 & 22.22 & 22 & 7.64 \\
\hline Opposition from other family members & 9.86 & 7.94 & - & 12 & 4.46 \\
\hline Opposition from husband & 2.82 & 7.94 & 14.81 & 7 & 5.09 \\
\hline Other causes & 5.63 & 6.35 & - & 8 & 100 \\
\hline Total No. & 70 & 61 & 26 & 157 & 100 \\
\hline$\%$ of caste wise never users & 44.59 & 38.85 & 16.56 & & \\
\hline
\end{tabular}

Source: personal survey based data

In the present study maximum $34.40 \%$ respondents of the never users mentioned fear of need of boy of the family planning methods as an important reason for non adoption. Ignorance (about use) and No knowledge appeared the third reason followed by scared of side effects and opposition from husband side. Opposition of family members has also been one of the reasons. Sexual dissatisfaction may be one component of other causes of non adoption. In Nepal also concern about surgery and its complications was cited as an important reason for non adoption of sterilization (Stash, S., 1995, and Khan, M.E. et al., 1985).

Also the fact that sterilization led to weakness $(56.86 \%)$ was also observed in Nepal (Shrestha, A. et al., 1988). Khan, M.E. et al., (1985) also made similar observations in U.P.

The study area under study has no Muslim population as such religion reason for opposing birth control method is absent. Muslims are less likely to be ever users. DHS reports from Bangladesh, Nigeria, Pakistan and Senegal revealed that more than $10 \%$ of the women with unmet need who did not intend to use contraception cited religious objections in Muslim living areas. Caste wise breakup of never users of family planning methods is presented in table 5 .

\section{Results for t-test and one-way ANOVA (Univariate analysis of variance)}

This study was conducting to compare the efficiency of the education, caste and income with the use of family planning methods. T-test used when making comparisons between Independent samples t-test analysis between use of family planning method and educational achievement the means of two samples or between some standard value and the mean of one sample. There are different varieties of t-tests which are used in different conditions depending on the design of the experiment or the nature of the data.

Table 6 results are given in three rows. The first row labeled Between Groups gives the variability due to the use (between-groups variability), the second row labeled Within Groups gives variability due to random error, and the third row gives the total variability. In the given result are showing, F-value is 11.202 and the corresponding p-value is given as $<0.0001$. Therefore we can safely reject the null hypothesis and conclude that the average use of the family planning methods.

There is a significant difference in the use of family planning methods, $F(2,361)=11.202$, $p<0.001$.

Table 6. Use of ANOVA variance between educational achievement and use of family planning method

\begin{tabular}{|c|c|c|c|c|c|}
\hline Source & Sum of Squares & df & Mean Square & $\mathrm{F}$ & $\begin{array}{c}\text { F Prob. } \\
\text { Sig. }\end{array}$ \\
\hline Between Groups & 7.525 & 3 & 2.508 & 11.202 & .0001 \\
\hline Within Groups & 80.831 & 361 & .224 & & \\
\hline Total & 88.356 & 364 & & & \\
\hline
\end{tabular}




\begin{tabular}{|c|c|c|c|c|c|c|c|}
\hline & Groups & $\begin{array}{l}\text { Education of } \\
\text { respondents }\end{array}$ & $\mathbf{N}$ & Mean & $\begin{array}{c}\text { Std. } \\
\text { Deviation }\end{array}$ & $\begin{array}{l}\text { Std. Error } \\
\text { Difference }\end{array}$ & t-value \\
\hline \multirow{12}{*}{ 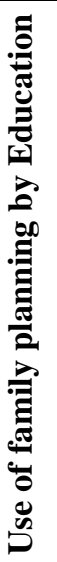 } & \multirow{3}{*}{$1-2$} & Illiterate & 124 & 1.73 & .444 & \multirow[t]{2}{*}{.062} & \multirow[t]{2}{*}{1.766} \\
\hline & & Primary & 104 & 1.63 & .486 & & \\
\hline & & Primary & 104 & 1.63 & .486 & \multirow[t]{2}{*}{.083} & \multirow[t]{2}{*}{.806} \\
\hline & \multirow[t]{2}{*}{$2-3$} & High school & 52 & 1.56 & .502 & & \\
\hline & & High school & 52 & 1.56 & .502 & \multirow[t]{2}{*}{.086} & \multirow[t]{2}{*}{2.380} \\
\hline & \multirow[t]{2}{*}{$3-4$} & Above high school & 85 & 1.35 & .481 & & \\
\hline & & Illiterate & 124 & 1.73 & .444 & \multirow[t]{2}{*}{.065} & \multirow[t]{2}{*}{5.892} \\
\hline & \multirow[t]{2}{*}{$1-4$} & Above high school & 85 & 1.35 & .481 & & \\
\hline & & Illiterate & 124 & 1.73 & .444 & \multirow[t]{2}{*}{.076} & \multirow[t]{2}{*}{2.311} \\
\hline & \multirow[t]{2}{*}{$1-3$} & High school & 52 & 1.56 & .502 & & \\
\hline & & primary & 104 & 1.63 & .486 & \multirow[t]{2}{*}{.071} & \multirow[t]{2}{*}{3.845} \\
\hline & $2-4$ & Above high school & 85 & 1.35 & .481 & & \\
\hline
\end{tabular}

The F-statistic in ANOVA only tells us that the dependent variable varies for different levels of factor(s). In case of more than two levels, the F-statistic does not tell us the exact way in which the dependent variable differs by the levels of factor(s). In this table we get results of the two tests- Levene's Test for Equality of Variance and t-test for Equality of Means. For example the difference between the groups score in group one and a second group score in within groups two would represent explained variance. The "Within Groups" variance represents what is often called "error variance". This is the variance within your groups, variance that is not due to the independent variable. Intuitively, it's important to understand that, at its heart, the analysis of variance and the $F$ score it yields is a ratio of explained variance versus error. This actual $F$ score (ratio) is in the column, and the probability of an $F$ probability of this magnitude is in column. As you can see this $F$ score is well below the .05 cut off, so that we can conclude then that the groups are statistically significantly different from one another. But two very important questions remain. Between groups, 2.508 means square are significantly different from which other means and, within groups were the actual scores .224 of the group. These comparisons are group 1 vs. 2,1 vs. 3,1 vs. 4 , etc.

The Post-Hoc test presents the result of the comparison between all the possible pairs. Since we have six groups, a total twelve pairs will be possible in which six will be mirror image (1-2, 1-3, 1-4 and 2-3, 2-4, 34). The results are shown in twelve rows. The t-value of any groups is not significantly different to each other between groups. There is the variable of educational qualification has not significantly associated to use of family planning methods.

The output is shown in the table 7 in the first table labeled between - subject's factors give the number of subjects and descriptive statistics gives us the mean, standard deviation and number of cases for the combination of different levels of the factors. In this case, we have 361 income groups of respondents belonging to each level of the two factors. In this case, from the first row of the descriptive statistics table, we can find that the mean income of respondents with use of family planning, second row in education with use of family planning and third row in total of respondents with use of family planning. The second table labeled relation between independent and dependent variables. The third labeled tests of between - subject's effects give the ANOVA results. The explanation for various columns is same as given earlier in case of One-Way ANOVA. We can see that the F-statistics corresponding to use of pair-1 (income-use of family planning) is 7.218 which are significant at $\mathrm{p}<.000$. F-statistic for educational background vs. use of family planning is 11.202 also highly significant at $\mathrm{p}<.0001$.

The results will be reported as:

Income groups and use of family planning has a significant effect on the pair-1, F $(3,361 \mathrm{df})=7.218$, $\mathrm{p}<.000$. However, education background is also highly significant $\mathrm{F}(3,361 \mathrm{df})=11.202, \mathrm{p}<.0001$. Test presents the result of the comparison between all the possible pairs. Since we have three groups, a total of income pairs will be possible in which three will be mirror images (1- 4 and 4-1, 2-4 and 4-2, 3-4 and 4-3). The results are shown in three rows. 
Table 7. Use of ANOVA variance analysis between two groups income of respondents and use of family planning method

\begin{tabular}{|l|r|r|r|r|r|}
\hline & \multicolumn{1}{|c|}{ Sum of Squares } & \multicolumn{1}{c|}{ df } & Mean Square & \multicolumn{1}{c|}{ F } & \multicolumn{1}{c|}{ Sig. } \\
\hline Between Groups & 5.000 & 3 & 1.667 & 7.218 & .000 \\
Within Groups & 83.356 & 361 & .231 & & \\
Total & 88.356 & 364 & & & \\
\hline
\end{tabular}

\begin{tabular}{|c|c|c|c|c|c|c|c|}
\hline & Groups & Income of respondents & $\mathbf{N}$ & Mean & $\begin{array}{c}\text { Std. } \\
\text { Deviation }\end{array}$ & $\begin{array}{l}\text { Std. Error } \\
\text { Difference }\end{array}$ & t-value \\
\hline \multirow{12}{*}{ 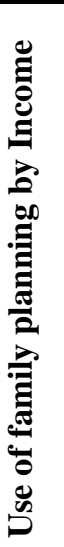 } & \multirow{3}{*}{$1-2$} & Below 2000 & 22 & 1.73 & .456 & \multirow{2}{*}{.106} & \multirow[t]{2}{*}{.000} \\
\hline & & $2000-3500$ & 99 & 1.73 & 448 & & \\
\hline & & $2000-3500$ & 99 & 1.73 & 448 & \multirow[t]{2}{*}{.085} & \multirow[t]{2}{*}{.322} \\
\hline & $2-3$ & $3500-5000$ & 40 & 1.70 & .464 & & \\
\hline & \multirow{3}{*}{$3-4$} & $3500-5000$ & 40 & 1.70 & .464 & \multirow[t]{2}{*}{086} & \multirow[t]{2}{*}{2.507} \\
\hline & & Above 5000 & 204 & 1.49 & .501 & & \\
\hline & & Below 2000 & 22 & 1.73 & .456 & \multirow[t]{2}{*}{.112} & \multirow[t]{2}{*}{2.170} \\
\hline & \multirow[t]{2}{*}{$1-4$} & Above 5000 & 204 & 1.49 & .501 & & \\
\hline & & $2000-3500$ & 99 & 1.73 & .448 & \multirow[t]{2}{*}{.059} & \multirow[t]{2}{*}{4.079} \\
\hline & \multirow[t]{2}{*}{$2-4$} & Above 5000 & 204 & 1.49 & .501 & & \\
\hline & & Below 2000 & 22 & 1.73 & .456 & \multirow[t]{2}{*}{.112} & \multirow[t]{2}{*}{.223} \\
\hline & $1-3$ & $3500-5000$ & 40 & 1.70 & .464 & & \\
\hline
\end{tabular}

The binary logistic regressions to get the adjusted effect of the predictor variables on the dependent variables have been applied here. The results of the logistic regressions are presented in table 8 . This table presents the results of logistic regression assessing the association between experience the use of family planning methods and the explanatory variables. The $95 \%$ confidence intervals are also presented in the table. The result shows that respondent's caste, education, occupation and age were significantly associated with use of family planning methods.

Table 8: Multivariate analysis of socio-economic status and use of family planning methods.

\begin{tabular}{|c|c|c|c|c|}
\hline \multirow[t]{2}{*}{ Selected variables } & \multirow[t]{2}{*}{ Sig. } & \multirow[t]{2}{*}{$\operatorname{Exp}(B)$} & \multicolumn{2}{|c|}{ 95.0\% C.I.for EXP(B) } \\
\hline & & & Lower & Upper \\
\hline \multicolumn{5}{|l|}{ Caste } \\
\hline Caste (General) $* *$ & .026 & 1.000 & & \\
\hline Caste (OBC) & .114 & .946 & .394 & 2.273 \\
\hline Caste (SC) & .633 & .814 & .351 & 1.891 \\
\hline \multicolumn{5}{|l|}{ Education } \\
\hline Above High School*** & .004 & 1.000 & & \\
\hline High School** & .033 & .720 & .375 & 1.381 \\
\hline Primary & .323 & .376 & .289 & 1.582 \\
\hline Illiterate & .367 & .345 & .166 & .716 \\
\hline \multicolumn{5}{|l|}{ Occupation } \\
\hline Labour & .497 & 1.000 & & \\
\hline Farmar & .141 & 1.006 & .195 & 1.262 \\
\hline Service** & .014 & 1.760 & .334 & 2.930 \\
\hline Business* & .065 & 1.147 & .109 & 2.754 \\
\hline \multicolumn{5}{|l|}{ Age group } \\
\hline Below 20 & .198 & 1.000 & & \\
\hline $20-30 * * *$ & .004 & .270 & .022 & 2.479 \\
\hline Above 30 & .202 & .236 & .026 & 2.173 \\
\hline \multicolumn{5}{|l|}{ Income } \\
\hline Above 5000 & .116 & 1.000 & & \\
\hline $3000-5000$ & .971 & .907 & .341 & 3.057 \\
\hline $1000-3000$ & .738 & .881 & .302 & 5.424 \\
\hline Below 1000 & .232 & .460 & .129 & 1.643 \\
\hline
\end{tabular}

Source: self computed 
The probability for opting of family planning methods is much higher in General caste (odds ratio 1.00) than OBC (odds .946) and SC (odds .814). An comparison of literate and illiterate respondents going for using of family planning methods. Similarly, below 20 years age (odds ratio 1.00) respondents have higher probability for the use of family planning methods than respondents above 20 years age group. Occupation of the candidate is also positively associated with use of family planning.

\section{DISCUSSION}

The present study revealed an inverse relationship between literacy status of self, literacy status of spouse and contraceptive use, a fact supported by many other studies (Westoff CF. et al. 1981; Lakshmi GR. et al. 1986; Bulatao RA. Et al. 1993 and Devi DR. et al. 1996). Women who were gainfully employed were more likely to have ever used a contraceptive method as also observed by Lloyed, Schuler and Hashemi (Lloyd CB. 1991 and Schuler SR. et al. 1994). Majority (75.5\%) of the women mentioned fear of side effects of the contraceptives to be the reason for never use. In many other countries such concerns about side effects of contraceptives originating from experience of friends and rumors which are told and retold through the communities have contributed to low contraceptive acceptance (Nag M. 1984). In the present study $62.75 \%$ of the never users who were scared of side effects mentioned fear of the procedure and anesthesia to be the reason. In Nepal also concern about surgery and its complications was cited as an important reason for non adoption of sterilization (Khan, ME. Et al. 1985 and Stash S. 1995). Also the fact that sterilization led to weakness $(56.86 \%)$ was also observed in Nepal (Shrestha A. et al. 1988). In the present study, 12.75\% of the women who were afraid of side effects fared pregnancy and $3.43 \%$ expressed concern about sexual dissatisfaction with condom use. Khan et al (Khan, ME. Et al. 1985) also made similar observations in U.P.

Never users of contraception were aware of fewer contraceptive methods as compared to ever users as also revealed by the Demographic and Health Survey conducted in Kenya where contraceptive users mentioned on an average four methods and non users less than three (Bulatao, RA. Et al. 1993).

$8.88 \%$ of the never users stated the reason to be husbands' opposition which can have serious consequences as observed in Sub Saharan countries were contraceptive use among women whose husbands disapproved of family planning averaged only one third as much as among women whose husbands approved of it (Ravindran TKS, 1993).

Religion was cited as a reason for opposition of contraceptive use by $31.85 \%$ of the subjects in the present study. Also Muslims were less likely to be ever users ( $\mathrm{p}<0.001$ ). DHS reports from Bangladesh, Nigeria, Pakistan and Senegal reveal that more than $10 \%$ of the women with unmet need who did not intend to use contraception cited religious objections. A multi pronged strategy aimed at sustained IEC efforts focusing on safety and beneficial effects of various contraceptives, clearing of miscontraception about side effects of contraceptives by family planning counselors and equal involvement of both husband and wife as one unit should be able to bring out an outcome favorable in terms of contraception use.

\section{Conclusion}

The One-Way ANOVA compare mean model has been applied to Contraceptive use data to estimate the preference factors for the adoption of spacing and terminal methods of family planning with respect to female literacy and socio-economic factors.

The success of the family planning programme has been constrained by several factors such as lack of support from all the section of society, lack of inputs and integrated approach including literacy, caste and income. It is realized that people will respond to the family planning programmme more readily, if they are assured of the survival of two children. This all would require a sustained and consistent effort towards motivation supported by practical programmes of improving health and socio- economic conditions of the people in the study area.

It is clear from the foregoing discussion that knowledge of family planning methods among female respondents is substantial and increasing gradually. The majority of women have favourable attitude towards family planning. However, there is a wide gap between the knowledge and the practice of contraception among women respondents. Female sterilization still appears the most popular contraceptive method for limiting the family size.

There is a need to shift from women centric approach to couple centric approach for family planning. The authors opine for strong political will and commitment of the people along with improved socio- economic condition, vigorous implementation of family planning strategies through mass campaign and adequate supply of family planning materials. Education appears an important predicator for increasing addoption of family planning programme. 


\section{References:}

[1] Banerjee, Bratati., 2004. Socio-economic and Cultural Determinants on Acceptance of Permanent Methods of Contraception, The Journal of Family Welfare, Vol. 50, No. 1, pp. 54-58.

[2] Bulatao, R.A., Levin, A., Boser., Green, C., 1993. Effective family planning programs. Washington D.C., World Bank, 110.

[3] Bulatao, R.A., Levin, A., Boser., Green, C., 1993. Effective family planning programs. Washington D.C., World Bank, 110.

[4] Devi, D.R., Rastogi, S.R., Retherford, R.D., 1996. Unmet need for family planning in Uttar Pradesh. 46 unpublished.

[5] Khan, M.E., Dastidar, S.K., and Bainathi, S., 1985. Not wanting children yet not practicing family planning. The journal of family welfare XXXII No. 3(12): 8.

[6] Lakshmi, G.R., and Bandopadhyay, S.S., 1986. Effect of education, economic status and occupation on fertility, Health and population - Perspectives and issues; 9(1): 42-51.

[7] Lloyd, C.B., 1991. The contribution of world fertility surveys to an understanding of the relationship between women's work and fertility. Studies in Family Planning; 22(3): 144-161.

[8] Nag, M., 1984. Some cultural factors affecting costs of fertility regulation. Population Bulletin of the United Nations, 17: 17-38.

[9] Pandey, S., and Singh, R., 2001. "Environment, caste and community in family planning knowledge attitude- behaviour relationship." Prachi Journal of Psycho Cultural Dimensions, 17(2): 103-108.

[10] Rajaretanam, T., 1995. Family size desire, sex preference, socio-economic condition and contraceptive use in rural Karnataka, India, Demography India, vol. 24(2).

[11] Ramesh, B.M, Gulati, S.C., and Retherford, D. Robert., 1996. Contraceptive use in India, NFHS subject report no. 2, International Institute for Population Science, Mumbai, India.

[12] Ravindran, T.K.S., 1993. Users perspectives on fertility regulation methods. Economic and political weekly Nov 13-20, : 25082512.

[13] Reddy, S., and Rajesh, et al., 2003. Rapid Appraisal of Knowledge, Attitude and Practices Related to Family Planning Methods Among Men Within 5 Years of Married Life, Indian Journal of Preventive \& Social Medicine, Vol. 34, No. 1 \& 2, pp. $62-67$.

[14] Schuler, S.R., and Hashemi, S.H., 1994. Increasing use of contraception by decreasing women's dependence and isolation: Credit programs and family planning outreach in Bangladesh Boston, John Snow; 7: 19.

[15] Shrestha, A., Stoeckel, J., and Taladhar, J.H., 1988. Factors related to non use of contraception among couples with an unmet need for family planning in Nepal, Kathmadhu, Nepal, New Era: 81.

[16] Singh,V. K. and Singh, M.B., 2007. Social Dynamic Status and its reflection on Use of Family Planning Methods in an Indian village: a case study of 'Gaura' (UP), India, The Third Pole, Vol. 5-7, pp 52-61.

[17] Stash, S., 1995. Reason for unmet need in Nepal: An attempt to pick up where fertility surveys leave off: 45 Unpublished.

[18] Westoff, C.F., and Pebley, A.R., 1981. Alternative measures of unmet need for family planning in developing countries. International Family Planning perspectives 7(4): 126-136. 